\title{
Bumetanide-acute and long term studies of a new high potency diuretic
}

\author{
W. R. MURDOCH \\ F.R.C.P., M.R.C.P.
}

\author{
W. H. R. Auld \\ M.D., F.R.C.Path.
}

Ballochmyle Hospital and Heathfield Hospital, Ayrshire

\begin{abstract}
Summary
The properties of a new diuretic, bumetanide, were investigated in ten normal volunteers, and sixty-eight patients with fluid retention. It had a rapid action virtually complete in $4 \mathrm{hr}$ with an effect on water and electrolyte excretion similar to that of frusemide. It was highly potent, $1 \mathrm{mg}$ producing an effect comparable to $48 \mathrm{mg}$ frusemide in normal subjects, and about $40 \mathrm{mg}$ in oedematous subjects in controlled shortterm experiments. In long-term studies in forty-eight patients extending over periods up to 51 weeks it was found to be effective in controlling oedema. There was a low incidence of electrolyte complications and no other biochemical abnormalities or haematological complications were attributed to the drug. Bumetanide was well tolerated by patients. A drug rash was observed in two cases.
\end{abstract}

\section{Introduction}

Bumetanide (Burinex) has been recently introduced as a potent diuretic with a rapid onset and short duration of action similar to that of frusemide, although some 40-60 times more potent on a weight basis (Asbury et al., 1972; Olesen et al., 1973; Davies et al., 1973). It is a derivative of metanilamide whereas frusemide and the thiazides are derived from sulphanilamide (Feit, 1971; Feit and Tvaermose Nielsen, 1972; Feit et al., 1972; Feit et al., 1973b).

In view of the potential value of this new compound we decided to try to confirm the acute response to bumetanide in healthy volunteers and oedematous patients, and to investigate the effects of long-term therapy in patients with moderate to severe oedema.

\section{Subjects and methods}

Acute studies

Healthy volunteers. Ten normal subjects were studied, all members of the medical staff. As far as possible they maintained a constant diet and fluid intake during the trial. They were instructed to collect urine samples in the following manner. At

Correspondence: DrW.R. Murdoch, Consultant Physician, Heathfield Hospital, Ayrshire KA8 9DZ.
8 a.m. the bladder was emptied and the contents discarded. Urine was then collected from 8 a.m. to noon, noon to 4 p.m., 4 p.m. to 8 p.m., 8 p.m. to midnight, and from midnight to the following 8 a.m. The total volume was noted and an aliquot kept for analysis. The first $24 \mathrm{hr}$ represented a control period. The full procedure was repeated on the second day, but the volunteer was given in random order either a $1 \mathrm{mg}$ tablet of bumetanide or a $40 \mathrm{mg}$ tablet of frusemide (Lasix) at 8 a.m. After a few days' interval the entire $48-\mathrm{hr}$ procedure was repeated using the other diuretic. Thus it was possible to obtain two control periods and to study the effect of each diuretic in turn. Urine samples were analysed by standard methods; sodium and potassium by flame photometry with an EEL photometer, chloride by the titrimetric method of Schales and Schales (1941), and the electrolyte content of each specimen was determined.

Patients. Twenty patients (fourteen male, six female) with clinical features of moderate fluid retention were studied. The nature of the investigation was explained to them and they voluntarily consented to participate. Their ages ranged from 48 to 80 years. Fourteen patients showed evidence of myocardial infarction or ischaemia associated with left ventricular failure. Four patients had congestive cardiac failure, two in association with chronic chest disease, one with hypertension, and one with pernicious anaemia. One patient had chronic active hepatitis with hypoproteinaemia and fluid retention and one patient had renal disease and fluid retention. Throughout the trial they remained on a standard light diet and were not allowed to take additional salt supplements. Existing therapy, e.g. digoxin, was maintained during the trial period. The investigation was not commenced until the patient had reached a stable condition in hospital and a control 24-hr collection of urine had been obtained.

The diuretics were given in the sequence ABBA or BAAB (Gold et al., 1960), thus eliminating a source of bias that is possible where one drug always precedes or follows the other in paired comparisons. Either sequence was given randomly to patients and was not known to the laboratory investigators until 
the end of the trial. As both diuretics appeared to have a short duration of action they were given on consecutive days. Including the control collection, five 24-hr urine samples were thus obtained from each patient and the urine volume and sodium, potassium and chloride content measured. Creatinine determinations were made to assess the completeness of urinary collections. The 24-hr increment in excretion of each parameter was derived by subtracting the basal value from the mean daily excretion with each diuretic.

\section{Long term investigations}

Forty-eight patients with moderate to severe oedema were treated with bumetanide in dosages ranging from 1 to $8 \mathrm{mg}$. Doses up to $2 \mathrm{mg}$ were given as a single morning dose; above $2 \mathrm{mg}$ the dose was divided and given in the morning and after lunch. A slow release potassium supplement was given to thirty-five patients, the dose varying from 24 to $48 \mathrm{mmol}$ potassium depending on the dose of bumetanide and the initial potassium level. Spironolactone was given to six patients with resistant oedema. No potassium supplement or spironolactone was given to nine patients who received a daily dose of $1 \mathrm{mg}$ of bumetanide/day. In all cases treatment was initiated in hospital. The volume of urine was measured daily and routine estimations of plasma urea, creatinine and electrolytes were made at frequent intervals during their stay. Particular attention was paid to the incidence of side effects. Blood counts and liver function tests, namely serum bilirubin, thymol turbidity and flocculation, alkaline phosphatase, total protein, albumin, asparate and alanine transaminases were monitored at approximately weekly intervals. Those patients discharged from hospital on maintenance therapy were assessed at monthly intervals.

\section{Results}

\section{Acute studies}

Healthy volunteers. The onset of action is rapid and occurs within an hour, the main diuretic effect being over within $4 \mathrm{hr}$. The pattern of response is thus similar to frusemide (see Fig. 1). As the diuresis induced by both compounds was of short duration, statistical analysis of results using Student's $t$ test was confined to the initial 4-hr excretion period of each volunteer. The mean increases above control in urine volume and sodium, potassium and chloride

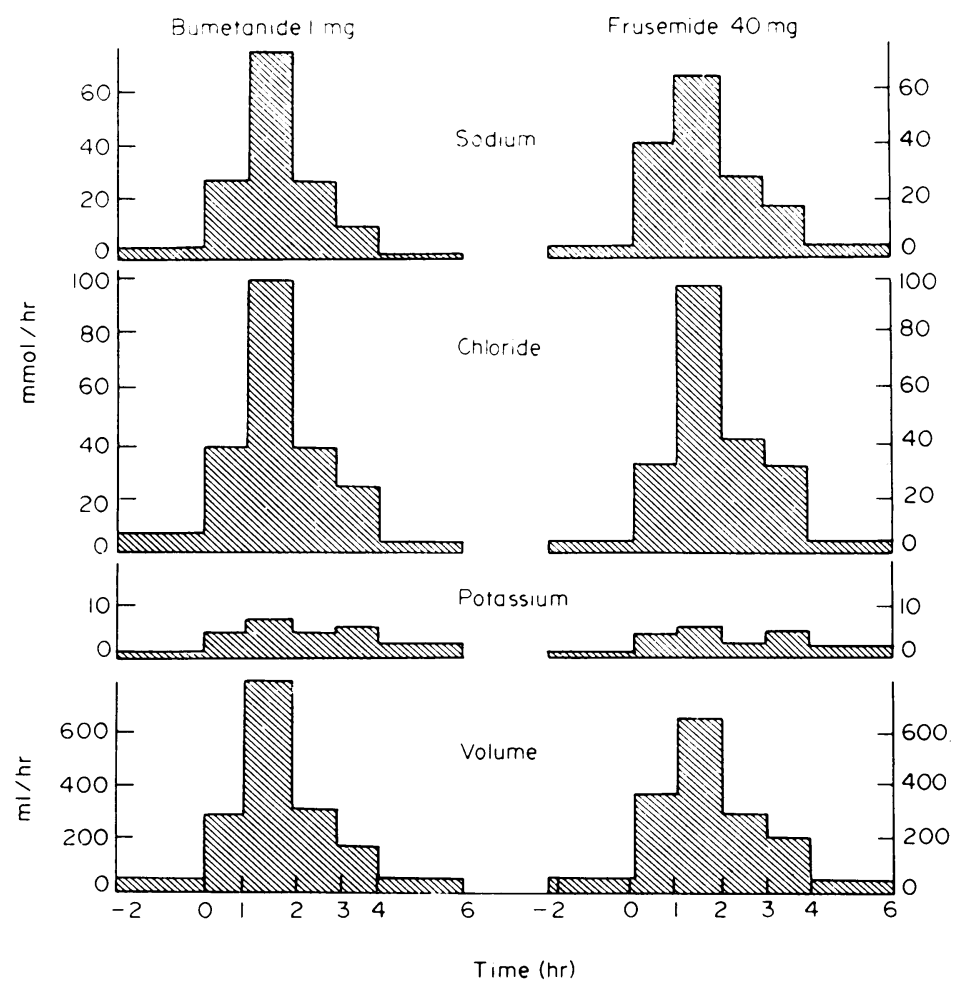

FIG. 1. Changes in urinary volume and electrolytes measured hourly in a healthy volunteer given bumetanide $1 \mathrm{mg}$ or frusemide $40 \mathrm{mg}$. For clarity, the scale for potassium is drawn enlarged. 
excretion are shown in Table 1. Although all responses were greater with bumetanide, the differences were not significant. The calculated potency ratio in normal subjects shows that $1 \mathrm{mg}$ bumetanide is equivalent to $48 \mathrm{mg}$ frusemide for urine volume, $47 \mathrm{mg}$ for sodium excretion, $47 \mathrm{mg}$ for potassium excretion and $48 \mathrm{mg}$ for chloride excretion respectively.

Patients. The mean 24-hr increases above control in urine volume and sodium, potassium and chloride excretion for each diuretic are given in Table 2. The responses to bumetanide and frusemide were remarkably similar in the doses used. Thus $1 \mathrm{mg}$ bumetanide is equivalent to $41 \mathrm{mg}$ frusemide for urine volume, $42 \mathrm{mg}$ for sodium excretion, $48 \mathrm{mg}$ for potassium excretion, and $40 \mathrm{mg}$ for chloride excretion respectively.

\section{Long term investigations}

The duration of treatment varied from 14 to 359 days in the forty-eight patients studied, with a mean of 74 days. The total number of patient-days was 3569 and the total amount of drug administered was $6589 \mathrm{mg}$.

In addition to congestive failure our series included five cases of renal disease with gross fluid retention and hypoproteinaemia. Eight patients had severe oedema which had proved resistant previously to various diuretic combinations including frusemide and spironolactone. We found bumetanide an effective diuretic over a wide dose range.

In general the drug was well tolerated. Vomiting was noted in two patients initially but this may have been due to their primary illness. The only significant adverse effect was the appearance of an itchy and erythematous rash in two patients. In both cases the rash appeared after treatment was started and disappeared when the drug was withdrawn. No significant change was noted in the blood count or liver function tests. It was interesting to note that in one of these patients a similar rash occurred when she was changed to frusemide.

Similarly in the remaining patients, routine blood counts and liver function tests showed no evidence of drug-induced disturbance even on long-term treatment.

A summary of the plasma electrolyte findings before and after bumetanide therapy is given in Table 3. Although individually the fall in plasma urea and creatinine levels was not significant, the combined trend would suggest an improvement in renal function as a result of treatment. There was no significant change in the plasma sodium levels. Five patients were hyponatraemic initially owing to their primary condition, but only one patient developed low plasma sodium values during the course of the trial.

TABLE 1. Increments in 4-hr urine volume and electrolyte excretion in ten normal subjects following bumetanide and frusemide. Mean values and statistical analysis

\begin{tabular}{lccccc}
\hline & \multicolumn{5}{c}{ Mean increase $( \pm$ s.d.) in inital 4-hr period } \\
\cline { 2 - 6 } & $\begin{array}{c}\text { Urine } \\
\text { volume } \\
(\mathrm{ml})\end{array}$ & $\begin{array}{c}\text { Sodium } \\
\text { excretion } \\
(\text { mmol) }\end{array}$ & $\begin{array}{c}\text { Potassium } \\
\text { excretion } \\
(\text { mmol) }\end{array}$ & $\begin{array}{c}\text { Chloride } \\
\text { excretion } \\
\text { (mmol) }\end{array}$ & $\begin{array}{c}\text { Ratio Na/K } \\
\text { excretion }\end{array}$ \\
\hline Bumetanide & 1127 & $129 \cdot 6$ & 19.5 & $164 \cdot 2$ & $6.6 / 1$ \\
& $(269)$ & $(36.8)$ & $(16.4)$ & $(50.8)$ & \\
Frusemide & 931 & 108 & 16.6 & 137.8 & $6.5 / 1$ \\
& $(274)$ & $(32 \cdot 3)$ & $(7 \cdot 7)$ & $(38.4)$ & \\
$t$ & 1.418 & $1 \cdot 395$ & 0.507 & 1.312 & \\
Significance & n.s. & n.s. & n.s. & n.s. & \\
\hline
\end{tabular}

TABLE 2. Increments in 24-hr urine volume and electrolyte excretion in twenty patients with fluid retention following bumetanide and frusemide therapy. Mean values and statistical analysis

\begin{tabular}{lccccc}
\hline & \multicolumn{5}{c}{ Mean increase ( \pm s.d.) per 24-hr period } \\
\cline { 2 - 6 } & $\begin{array}{c}\text { Urine } \\
\text { volume } \\
(\mathrm{ml})\end{array}$ & $\begin{array}{c}\text { Sodium } \\
\text { excretion } \\
(\mathrm{mmol})\end{array}$ & $\begin{array}{c}\text { Potassium } \\
\text { excretion } \\
(\text { mmol) }\end{array}$ & $\begin{array}{c}\text { Chloride } \\
\text { excretion } \\
\text { (mmol) }\end{array}$ & $\begin{array}{c}\text { Ratio Na/K } \\
\text { excretion }\end{array}$ \\
\hline Bumetanide & 697 & 73 & 13.9 & 78.4 & $5 \cdot 7 / 1$ \\
& $(383)$ & $(51 \cdot 2)$ & $(19 \cdot 1)$ & $(51 \cdot 2)$ & \\
Frusemide & 683 & 69.5 & 11.4 & 79.4 & $6 \cdot 1 / 1$ \\
& $(419)$ & $(57 \cdot 4)$ & $(15.8)$ & $(55)$ & \\
$t$ & 0.106 & 0.218 & 0.460 & 0.059 & \\
Significance & n.s. & n.s. & n.s. & n.s. & \\
\hline
\end{tabular}


TABle 3. Plasma urea, creatinine, and electrolyte values before and after long-term treatment with bumetanide in forty-eight patients. Mean values ( \pm s.d.) and statistical analysis

\begin{tabular}{lcccccc}
\hline & $\begin{array}{c}\text { Urea } \\
(\mathrm{mg} / 100 \mathrm{ml})\end{array}$ & $\begin{array}{c}\text { Creatinine } \\
(\mathrm{mg} / 100 \mathrm{ml})\end{array}$ & $\begin{array}{c}\text { Sodium } \\
(\mathrm{mmol} / \mathrm{l})\end{array}$ & $\begin{array}{c}\text { Potassium } \\
(\mathrm{mmol} / \mathrm{l})\end{array}$ & $\begin{array}{c}\text { Chloride } \\
(\mathrm{mmol} / \mathrm{l})\end{array}$ & $\begin{array}{c}\text { Bicarbonate } \\
(\mathrm{mmol} / \mathrm{l})\end{array}$ \\
\hline Before treatment & $53 \cdot 5$ & $1 \cdot 52$ & $139 \cdot 5$ & $3 \cdot 86$ & $99 \cdot 6$ & $26 \cdot 1$ \\
& $(31 \cdot 3)$ & $(1 \cdot 2)$ & $(5 \cdot 0)$ & $(0 \cdot 7)$ & $(5 \cdot 4)$ & $(4 \cdot 7)$ \\
After treatment & 49.9 & $1 \cdot 31$ & $139 \cdot 3$ & $4 \cdot 01$ & $97 \cdot 9$ & $27 \cdot 3$ \\
& $(26.5)$ & $(0 \cdot 8)$ & $(5 \cdot 2)$ & $(0 \cdot 5)$ & $(5 \cdot 8)$ & $(4 \cdot 1)$ \\
$t$ & 0.5690 & 0.8949 & $0 \cdot 1952$ & $1 \cdot 1368$ & $1 \cdot 3126$ & $1 \cdot 2765$ \\
Significance & n.s. & n.s. & n.s. & n.s. & n.s. & n.s. \\
\hline
\end{tabular}

Plasma potassium levels rose slightly from a mean of 3.86 to $4.01 \mathrm{mmol} / 1$ during therapy, probably indicating that the dosage of potassium supplement or spironolactone was adequate. No instance of severe hypokalaemia was noted even in the nine patients who received $1 \mathrm{mg}$ bumetanide/day without potassium supplements for periods ranging from 14 to 239 days (mean 71 days). In these patients, the mean plasma potassium level before treatment was 4.16 (s.d. \pm 0.96 ) and after treatment was 4.06 (s.d. \pm 0.56 ). Two patients showed a moderate rise in plasma bicarbonate possibly indicative of metabolic alkalosis resulting from treatment. However, the overall mean figures showed no significant change.

Serial serum uric acid determinations were made in eighteen patients for periods ranging from 14 to 359 (mean $=110)$ days. Six patients showed hyperuricaemia (serum uric acid $>7 \mathrm{mg} / 100 \mathrm{ml}$ ) before starting bumetanide treatment. Five of these had previously been treated with frusemide and one had renal failure. Of the remaining twelve, the mean pre-treatment serum uric acid level was $5.71 \mathrm{mg} /$ $100 \mathrm{ml}$ (s.d. 0.82 ) and $6.42 \mathrm{mg} / 100 \mathrm{ml}$ (s.d. 1.35) towards the end of bumetanide therapy. This change was not statistically significant. No manifestations of gout were observed.

No patient developed glycosuria. In the five diabetic patients it was not necessary to change the maintenance doses of insulin or hypoglycaemic drugs. Routine urine analysis showed no significant change.

\section{Discussion}

Our short-term studies have amply confirmed that bumetanide is a highly potent diuretic, $1 \mathrm{mg}$ having an action similar to $48 \mathrm{mg}$ frusemide in normal subjects, and $41 \mathrm{mg}$ in oedematous patients. These figures compare with a ratio of $1: 40$ found by Asbury et al. (1972) and Olesen et al. (1973), and 1 : 60 found by Davies et al. (1973). The rapid absorption from the gastro-intestinal tract is reflected in the brisk diuresis established within the hour, maximal within $2 \mathrm{hr}$, and virtually complete within $4 \mathrm{hr}$ of administration, thus making it a valuable drug for emergency use. It would appear that the saluretic effect obtained is paralleled by the renal excretion of the unconjugated drug (Feit et al., 1973a). We have found the pattern of fluid and electrolyte excretion to be similar to frusemide, and there is evidence that both the drugs have a similar locus of action on the ascending limb of the loop of Henle (Olesen et al., 1973). It has been suggested that bumetanide has an additional action on the proximal tubule (Bourke et al., 1973).

Nevertheless, the eventual place of a new diuretic depends on careful long-term assessment of its effectiveness in a variety of clinical conditions. So far few studies are available. Asbury et al. (1972) treated eleven patients by continuous oral administration of 1-2 mg of the drug for a period of 8 days. Davies et al. (1973) in a comprehensive investigation of the pharmacological properties of the drug, treated twelve patients for a minimum period of 7 weeks with satisfactory control of oedema. Three patients were withdrawn from the series, two on account of asymptomatic hyperuricaemia, and a third because of abnormal liver function tests not attributable to the drug. The largest long term investigation reported is that of Olesen et al. (1973) who treated thirty-two patients ranging from 1 month to 13 months, using a dosage range from 2 to $4 \mathrm{mg}$ of bumetanide per day. They obtained an effective diuresis with minimal changes in blood chemistry, haematological status or liver function.

Our study comprising forty-eight patients treated for periods ranging from 2 to 51 weeks with a mean of 10 weeks confirms that bumetanide is a potent diuretic effective over a wide dosage range and in a variety of clinical conditions.

Adverse side effects have in the past seriously curtailed the use of otherwise promising drugs. So far it has been encouraging to find a low incidence in patients treated with bumetanide. Olesen et al. (1973) reported muscle cramps in two patients during diuresis. Early in our series two patients developed skin rashes attributable to the drug, but there were no other reactions. We found no adverse effect on hepatic or renal function. Indeed, in our series the trend to a fall in plasma urea and creatinine 
might suggest an improvement in renal function with continued treatment.

As with other diuretics, bumetanide increases the excretion of potassium. Nevertheless, there was no evidence of severe hypokalaemia, even in the group of nine patients who did not receive potassium supplements. Thus in low dosage therapy the dietary intake of potassium may be sufficient. Supplements would be required where this falls below $60 \mathrm{mmol} /$ day, for example in elderly patients (Judge, 1972).

Bumetanide has been shown in other studies to produce a rise in serum uric acid levels with continued treatment (Asbury et al., 1972; Olesen et al., 1973). No significant rise was observed in the present series and no patient showed clinical evidence of gout.

As with Olesen et al. (1973), we found no untoward effects on carbohydrate metabolism during this trial, and several diabetic patients were treated without their regime having to be altered.

\section{Acknowledgments}

Our thanks are due to Dr R. Hill and Dr A. Slessor for helpful criticism and for permission to treat patients under their care. We are grateful to Mr P. N. Underwood of Leo Laboratories Ltd for supplies of bumetanide.

\section{References}

Asbury, M.J., Gatenby, P.B.B., O'Sullivan, S. \& Bourke, E. (1972) Bumetanide: potent new 'loop' diuretic. British Medical Journal, i, 211.

Bourke, E., Asbury, M.J., Gatenby, P.B.B. \& O'Sullivan, S. (1973) The sites of action of bumetanide in man. European Journal of Pharmacology, 23, 283.
Davies, D.L., Lant, A.F., Millard, N.R., Smith, A.J., WARD, J.W. \& WiLSON, G.M. (1974) Renal action, therapeutic use and pharmacokinetics of the diuretic bumetanide. Clinical Pharmacology and Therapeutics, 15, 141.

FeIT, P.W. (1971) Aminobenzoic acid diuretics. 2. 4-substituted - 3 - amino - 5 - sulphamylbenzoic acid derivatives. Journal of Medicinal Chemistry, 14, 432.

Feit, P.W. \& Tvaermose Nielsen, O.B. (1972) Aminobenzoic acid diuretics. 3. 4-substituted-5-sulfamylanthranilic acid derivatives. Journal of Medicinal Chemistry, 15, 79.

Feit, P.W., Tvaermose Nielsen, O.B. \& BruUn, H. (1972) Structure-activity studies on sulfamyl diuretics. Journal of Medicinal Chemistry, 15, 437.

Feit, P.W., Roholt, K. \& Sorensen, H. (1973a) GLC determination and urinary recovery of bumetanide in healthy volunteers. Journal of Pharmaceutical Sciences, 62, 375.

Feit, P.W., Tvaermose Nielsen, O.B. \& Rastrup-AnderSEN, N. (1973b) Aminobenzoic acid diuretics. 4. 4-benzyl-5sulfamylanthranilic acid derivatives and related 1,2benzisothiazole 1,1-dioxides. Journal of Medicinal Chemistry, 16, 127.

Gold, H., Kwit, N.T., Messeloff, C.R., Kramer, M.L., Colfins, A.J., Greiner, T.H., Goessel, E.A., Hughes, J.H. \& WARSHAW, L. (1960) Comparison of Chlorothiazide and Meralluride. New rapid methods for quantitative evaluation of diuretics in bed patients in congestive heart failure. Journal of the American Medical Association, 173, 745.

Judge, D.T.G. (1972) In: Nutrition in Old Age (Ed. by L. A. Carlson), p. 86. Almquist and Wiksell: Uppsala.

Olesen, K.H., Sigurd, B., Steiness, E. \& LeTh, A. (1973) Bumetanide, a new potent diuretic. A clinical evaluation in congestive heart failure. Acta medica scandinavica, 193, 119.

Schales, O. \& Schales, S.S. (1941) A simple and accurate method for the determination of chloride in biological fluids. Journal of Biological Chemistry, 140, 879. 